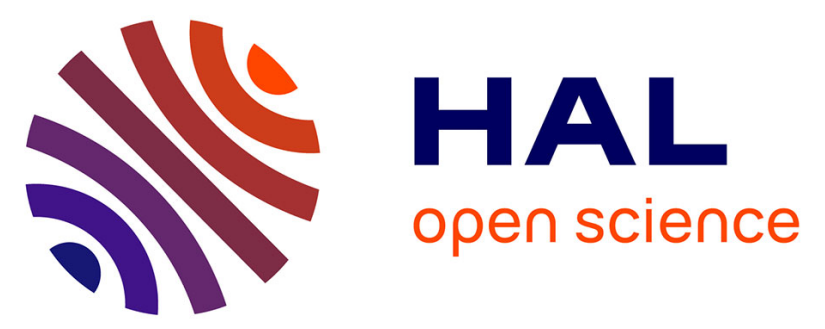

\title{
Effect of size and shape of metal particles to improve hardness and electrical properties of carbon nanotube reinforced copper and copper alloy composites
}

Sheikh M. Uddin, Tanvir Mahmud, Christoph Wolf, Carsten Glanz, Ivica Kolaric, Christoph Volkmer, Helmut Höller, Ulrich Wienecke, Siegmar Roth, Hans-Jörg Fecht

\section{To cite this version:}

Sheikh M. Uddin, Tanvir Mahmud, Christoph Wolf, Carsten Glanz, Ivica Kolaric, et al.. Effect of size and shape of metal particles to improve hardness and electrical properties of carbon nanotube reinforced copper and copper alloy composites. Composites Science and Technology, 2010, 70 (16), pp.2253. 10.1016/j.compscitech.2010.07.012 . hal-00696568

\section{HAL Id: hal-00696568 https://hal.science/hal-00696568}

Submitted on 12 May 2012

HAL is a multi-disciplinary open access archive for the deposit and dissemination of scientific research documents, whether they are published or not. The documents may come from teaching and research institutions in France or abroad, or from public or private research centers.
L'archive ouverte pluridisciplinaire HAL, est destinée au dépôt et à la diffusion de documents scientifiques de niveau recherche, publiés ou non, émanant des établissements d'enseignement et de recherche français ou étrangers, des laboratoires publics ou privés. 


\section{Accepted Manuscript}

Effect of size and shape of metal particles to improve hardness and electrical properties of carbon nanotube reinforced copper and copper alloy composites

Sheikh M. Uddin, Tanvir Mahmud, Christoph Wolf, Carsten Glanz, Ivica Kolaric, Christoph Volkmer, Helmut Höller, Ulrich Wienecke, Siegmar Roth, Hans-Jörg Fecht

PII: S0266-3538(10)00269-1

DOI: 10.1016/j.compscitech.2010.07.012

Reference: CSTE 4766

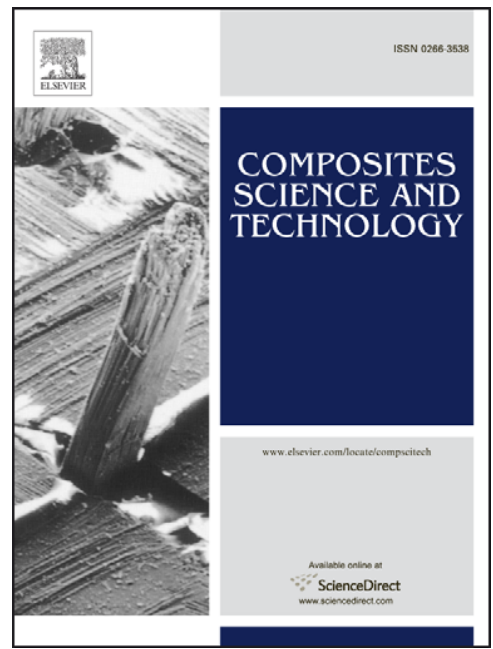

To appear in:

Composites Science and Technology

Received Date:

17 December 2009

Revised Date:

14 June 2010

Accepted Date:

12 July 2010

Please cite this article as: Uddin, S.M., Mahmud, T., Wolf, C., Glanz, C., Kolaric, I., Volkmer, C., Höller, H., Wienecke, U., Roth, S., Fecht, H-J., Effect of size and shape of metal particles to improve hardness and electrical properties of carbon nanotube reinforced copper and copper alloy composites, Composites Science and Technology (2010), doi: 10.1016/j.compscitech.2010.07.012

This is a PDF file of an unedited manuscript that has been accepted for publication. As a service to our customers we are providing this early version of the manuscript. The manuscript will undergo copyediting, typesetting, and review of the resulting proof before it is published in its final form. Please note that during the production process errors may be discovered which could affect the content, and all legal disclaimers that apply to the journal pertain. 
Effect of size and shape of metal particles to improve hardness and electrical properties of carbon nanotube reinforced copper and copper alloy composites

Sheikh M. Uddin ${ }^{1,5^{*}}$, Tanvir Mahmud ${ }^{2}$, Christoph Wolf ${ }^{2}$, Carsten Glanz ${ }^{2}$, Ivica Kolaric $^{2}$, Christoph Volkmer ${ }^{3}$, Helmut Höller ${ }^{3}$, Ulrich Wienecke ${ }^{3}$, Siegmar Roth $^{1,4}$ and Hans-Jörg Fecht ${ }^{5}$

${ }^{1}$ Sineurop Nanotech GmbH, Nobelstrasse 15, 70569 Stuttgart, Germany

${ }^{2}$ Fraunhofer IPA, Nobelstrasse 12, 70569 Stuttgart, Germany

${ }^{3}$ Bögra Technologie GmbH, Solingen, Germany

${ }^{4}$ School of Electrical Engineering, Korea University, Seoul, Korea

${ }^{5}$ Institute of Micro and Nano Materials, University of Ulm, Germany

Received 07 September 2009, revised 14 June 2010, accepted .............

Published online

*Corresponding author: Sheikh Minhaz Uddin, e-mail: minhaz.uddin@uni-ulm.de, Phone: +49 1766125 7277, Fax: +49 7119703995 


\section{Abstract}

Utilizing the extra-ordinary properties of carbon nanotube (CNT) in metal matrix composite (MMC) for macroscopic applications is still a big challenge for science and technology. Very few successful attempts have been made for commercial applications due to the difficulties incorporating CNTs in metals with up-scalable processes. CNT reinforced copper and copper alloy (bronze) composites have been fabricated by well established hot-press sintering method of powder metallurgy. The parameters of CNTmetal powder mixing and hot-press sintering have been optimized and the matrix materials of the mixed powders and composites have been evaluated. However, the effect of shape and size of metal particles as well as selection of carbon nanotubes has significant influence on the mechanical and electrical properties of the composites. The hardness of copper matrix composite has improved up to $47 \%$ compared to that of pure copper, while the electrical conductivity of bronze composite has improved up to $20 \%$ compared to that of the pure alloy. Thus carbon nanotube can improve the mechanical properties of highly-conductive low-strength copper metals, whereas in lowconductivity high-strength copper alloys the electrical conductivity can be improved.

Keywords: A. Carbon nanotubes, A. Metal matrix composites, B. Mechanical Properties, B. Electrical Properties, E. Hot-pressing, Copper and Copper alloys 


\section{Introduction}

Carbon nanotubes (CNTs) have received considerable interest in research due to their unique atomic structure and fascinating properties. Till now, the theoretical and experimental results achieved indicate that CNTs are the most unique and versatile materials so far discovered in the world. CNTs have an extremely high Young's modulus of 0.5-2 TPa [1-6], large ultimate tensile strength of 20-150 GPa [1, 2, 4, 7-9] and usually high flexibility $[3,10]$. Other than their exceptional mechanical properties, CNTs have an extremely high aspect ratio, excellent chemical stability as well as superior thermal and electrical properties. All these characteristics have made CNTs outstanding reinforcement materials for developing advanced nanocomposites for various applications.

Considerable researches have been conducted in carbon nanotube reinforced polymer matrix composites with a remarkable enhancement in mechanical properties compared to those of monolithic materials. However, limited research has been done in preparation, structural, physical and mechanical properties of metal-CNT nanocomposites. Poor wetting behaviour or weak interfacial bonding to matrix materials, agglomeration among themselves with Van-der-Waals force, inhomogeneous distribution of CNTs in the matrices and degraded thermal stability at high processing temperature are the prime drawbacks to use carbon nanotubes as reinforcements of metal matrix composites. For instance, Kuzumaki et al. reported very little improvement in tensile strength of CNT reinforced Al nanocomposites prepared by conventional powder mixing, hot pressing followed by hot extrusion due to inhomogeneous dispersion of CNTs in the metal matrix [11]. Moreover, carbon nanotubes as 
reinforcements of metal matrix composites have so far been reported poor efficiency [12-14] due to agglomeration among themselves with Van-der-Waals force, poor wetting behaviour or weak interfacial bonding to matrix materials [15-17] and degraded thermal stability at high sintering temperature [12, 18-20].

For any case, the homogeneous dispersion of nanotubes in metal matrices is the prime requirement before fabricating carbon nanotube based metal matrix nanocomposites. Early studies [21] of the authors showed that, high energy mechanical alloying involved continuous impact, welding, fracturing and rewelding of powders to disperse nanotubes in the metal powders. Different milling and sintering parameters were optimized for CNT-Al and CNT-Cu nanocomposites. In this contribution, we report on the successful preparation of CNT reinforced copper and bronze composites by mechanical mixing of nanotubes and metal powders followed by well-known hot-press sintering method of powder metallurgy. The effect of shape and size of metal particles to improve hardness of CNT-Cu composites and selection of nanotubes (single-walled or multi-walled) to improve electrical properties of CNT-Bronze composites have been investigated.

\section{Experimental}

\subsection{Materials}

Multi-walled nanotube (MWNT) with an average diameter of (10-20) nm, a length of $(0,5-200) \mu \mathrm{m}$ from Ahwahnee Technology Inc. and single-walled nanotube (SWNT) with a diameter of $<2 \mathrm{~nm}$, a length of (5-20) $\mu \mathrm{m}$ from Shenzhen Dynanonic Co., Ltd. were used as nanotube starting materials. Both types of nanotube were fabricated by the 
catalysis of hydrocarbon with chemical vapour deposition (CVD) process. Very pure copper powder (purity $>99.95 \%$ ) of $3 \mu \mathrm{m}$ particle size with dendritic shape, $10 \mu \mathrm{m}$ particle size with spherical shape from Sigma-Aldrich and $45 \mu \mathrm{m}$ particle size with spherical shape from TLS Technik GmbH were chosen as staring copper metal powders. The metal powders as alloying elements ( $\mathrm{Sn}, \mathrm{Zn}, \mathrm{Ni}$ ) with $45 \mu \mathrm{m}$ particle size, spherical shape were also used from TLS. The typical composition for fabricating bronze composites was $\mathrm{Cu} 79 \%$, Sn 10\%, Zn 3\% and Ni 8\%. Dendritic Copper Powders, more commonly referred to electrolytic copper powders (ECP) were produced by the electrolytic deposition method, whereas spherical metal powders are manufactured by atomization (gas/water) process. Table 1 and 2 shows the specification of nanotubes as well as metal particles.

\section{Table 1}

Table 2

\subsection{Mixing powders}

Different wt $\%$ of CNTs were mixed with metal powders inside a glove box having inert (Ar) atmosphere and milled in a planetary ball-mill machine (PM 400) for different hours with the following parameters: number of balls: 50 (stainless steel, hardness 48$52 \mathrm{HRC}$ ), diameter of each ball: $10 \mathrm{~mm}$, ball to powder ratio 10:1, milling speed: 200

rpm. Scanning electron microscopic (SEM, JEOL 6500) investigations were carried out to evaluate the dispersion of CNT in metal powders after the milling process. Different milling times and wt $\%$ of CNTs were used to ensure better dispersion of nanotubes in different metal powders.

\subsection{Composite fabrication}


The mixed powders were then sintered in a hot-press sintering machine (DSP 510) filled in inert (Ar) atmosphere. The DSP 510 sintering device using direct resistance heating in the mould produces very high heating speed and the whole composite fabrication process needs maximum 15 minutes. The sintering parameters (temperature, pressure, time, heating and cooling rate) were optimized for each type of composite by approaching their theoretical densities. The densities of the composites were measured using Archimedes' principle. Sintering temperature of $750{ }^{\circ} \mathrm{C}$ and pressure of $40 \mathrm{MPa}$ were used for $\mathrm{Cu}-\mathrm{CNT}$ composites, where as $800{ }^{\circ} \mathrm{C}$ and $40 \mathrm{MPa}$ were used for bronzeCNT composites fabrication.

\subsection{Characterization of the composites}

Before characterization, composite samples were ground with consecutive finer SiC abrasive papers followed by polishing with a diamond grit suspension up to one micrometer. The samples were then examined with light optical microscopy (LOM, Axio Imager from Carl Zeiss) etched with Ferric Nitrate or Chloride. Scanning electron microscopy (SEM, JEOL 6500) attached with Energy Dispersive Xray $(\mathrm{EDX})$ was used to evaluate the distribution of nanotubes in the matrix materials as well as to analyze the elements in the composite materials. The hardness of the composites was measured in the 3000 BLD Brinell hardness tester from WilsonWolpert using a $10 \mathrm{~mm}$ steel ball as an indenter with a $3000 \mathrm{kgf}(30 \mathrm{kN})$ force. Electrical conductivity of the composites was measured by a device called Sigmatest 2.069 , which measures the electrical conductivity of non-ferromagnetic metals by measuring the eddy current based on the complex impedance of the sample. When 
unknown test pieces are measured, this instrument converts the complex impedance value to an electrical conductivity value.

\section{Results and discussions}

\subsection{Evaluation of mixing}

In the early contribution [21], the authors showed that the planetary ball mill employed a strong centrifugal force to develop high energy milling action inside the vial, which in fact involved continuous impact, welding, fracturing and rewelding of CNT-metal powders. Milling for shorter time (30 minutes) did not show good embedment of CNTs in the matrix materials and prolonged milling promoted cold-welding of metal powders producing very large metal particles. By reducing the particle size of metals, the possibility to disperse CNTs in metal powders increases. Milling of $0.5 \mathrm{wt} \%$ of CNTs with $3 \mu \mathrm{m}$, dendritic copper particles for 1 hour showed very good distribution of CNTs in the metal particles (Fig. 1.a). The dendritic shape of the metal particles with its higher specific surface area [22] in this regard is expected to enhance nanotube distribution within the dendritic arms of the metal powders. Dispersion of CNTs is also promoted by milling with different alloying elements to produce CNT-Bronze composites (Fig. 1.b). CNTs are expected to diffuse in the different metal powders during mechanical alloying.

Figure 1

\subsection{Evaluation of composites}

After evaluating nanotube-metal mixed powders, composites were fabricated by a hotpress sintering method with optimized sintering parameters. Table 3 shows sintering 
parameters used for the composite fabrication and their corresponding relative densities. The density of nanotubes was considered to be $2 \mathrm{~g} / \mathrm{cm}^{3}$ [23]. Reducing the particle size of metals, the relative density of the composite is increased. $99.33 \%$ of the theoretical density was achieved with the composite made of $10 \mu \mathrm{m}$, spherical $\mathrm{Cu}$ particles. On the other hand, particles having dendritic shape should have less density (the more regular the shape, the denser the powder [24]) compared to that of spherical structure. Increasing CNT contents decreases the relative density of the composites due to increased porosities and voids inside the tubes and among the agglomeration of CNTs. Table 3

The early issue [21] already showed that CNTs were very uniformly distributed throughout the whole matrix and well-embedded in the matrix materials. The distribution of nanotubes was analysed from the fracture surface of the composites by scanning electron microscopy. The microstructure of the composites was also evaluated by Light Optical Microscopy (LOM). The micrograph (Fig. 2.a) showed two types of phases, one of which is completely CNT free, where CNTs are not distributed in the matrix and the other is $\mathrm{CNT} / \mathrm{Cu}$ phase, where CNTs are distributed inside Cu matrix. The distribution of CNTs in the matrix depends on the mixing of CNT-metal powders [25]. If CNTs are well distributed within metal powders during the ball-milling process, more homogeneous distribution of nanotubes is obtained. However, during the solidification process, the primary phase of pure $\mathrm{Cu}$ is formed shifting nanotubes towards the grain boundaries, while the other phase contains CNTs in Cu matrix [26]. A clear distinction between the two phases is shown in Fig. 2.a. The primary $\mathrm{Cu}$ phase appears as bright, whereas 
other phase contains CNTs as black dots inside Cu matrix. However, some black dots may also be appeared for copper (II) Oxide. Energy Dispersive X-ray (EDX) analysis on the surface of the same composite also ensured the presence of $\mathrm{Cu}, \mathrm{O}$ and $\mathrm{C}$ in the composite. Since copper does not form carbides, the carbon peak in EDX is an evidence of carbon nanotubes in the sample.

Figure 2

\subsection{Characterization of composites}

\section{Hardness}

Hardness of CNT-based Cu matrix composites was measured in a Brinell scale (29 kN force and with a steel ball). It was plotted against increasing proportions of CNTs. Figure 3 shows the Brinell hardness values of CNT-Cu and CNT-Bronze composites fabricated with $45 \mu \mathrm{m}$, spherical metal powders and different wt\% of MWNTs. According to D.L. Erich [27], discontinuous MMCs formed by the mixtures of individual metal phases exhibits strengths as much as $50 \%$ higher than those predicted in theory from the strength of the individual constituents. In our case, the hardness of pure $\mathrm{Cu}$ fabricated by hot-press sintering was also found almost double (58 HB) compared to that of reference value $(35 \mathrm{HB})$. However, the hardness decreases with increasing amount of CNTs in the composite for both CNT-Cu and CNT-Bronze composites.

Figure 3

Hardness of pure $\mathrm{Cu}$ and $\mathrm{Cu}-0.5 \mathrm{wt} \%$ MWNT composites with different particle size and shape (45 $\mu \mathrm{m}$, spherical; $10 \mu \mathrm{m}$, spherical and $3 \mu \mathrm{m}$, dendritic) is plotted in Fig. 4. Hardness values of pure $\mathrm{Cu}$ composites fabricated with $45 \mu \mathrm{m}, 10 \mu \mathrm{m}$ and $3 \mu \mathrm{m}$ remain 
in the similar range of 56-60 HB. However, hardness of $\mathrm{Cu}-\mathrm{CNT}(0.5 \mathrm{wt} \%)$ increases significantly by reducing the size of $\mathrm{Cu}$ particles. Obviously, there should be a certain effect of Hall-Petch relationship for the increase of hardness with particle size reduction. In our case, we did not find it significantly with pure $\mathrm{Cu}$ materials. However, reduction of particle size influenced a lot with nanotube incorporation. Distribution of CNTs in the matrix materials with reduced particle size of metals increases, which in turn plays a role to increase the hardness of the composites. Moreover, the dendritic structure of metal particles enhancing the CNT distribution in the matrix is also expected to improve the strength of the composite materials.

Figure 4

High interface due to reduced particle size of $\mathrm{Cu}$ and more homogeneous distribution of CNTs surrounding the dendritic arms of $\mathrm{Cu}$ particles provide higher interfacial strength with higher relative densities, which in fact help to distribute the external load from matrix to CNTs by sound interfacial strength at CNT/matrix. The hardness of composites fabricated with nanotubes and $3 \mu \mathrm{m}$, dendritic $\mathrm{Cu}$ metal particles is improved in this way. Hardness of $\mathrm{Cu}-\mathrm{CNT}(0.5 \mathrm{wt} \%)$ composites is increased up to $42 \%$ by using $3 \mu \mathrm{m} \mathrm{Cu}$ metal particles. However, the best hardness value (83.5 HB) was achieved in the composite fabricated with $3 \mu \mathrm{m}$, dendritic $\mathrm{Cu}$ particles and $0.1 \mathrm{wt} \%$ MWNT (Fig. 5). Therefore, hardness of Cu-CNT (0.1 wt \%) composites can be improved up to $47 \%$ by using $3 \mu \mathrm{m} \mathrm{Cu}$ particles in the composites. Further increasing CNT contents rather decreases the hardness of the composite.

Figure 5

\section{Electrical Conductivity}


Improvement of electrical conductivity of a highly conductive metal is still a big question of science. A composite based on aligned, ballistic conducting carbon nanotubes embedded in a metal matrix might work as an ultra-low-resistive material [28]. Moreover, in a sintering body of powder metallurgy, it is difficult to achieve $100 \%$ density of the theoretical density. There will be a certain amount of porosity inside the composite. These porosities are in fact the insulation sites which reduce the conductivity of the composites. Fig. 6 shows the electrical conductivity of the pure copper composite as $58 \mathrm{MS} / \mathrm{m}$, which is a little bit lower compared to reference conductivity (59.59 MS/m). Increasing CNT contents in the $\mathrm{Cu}$ composites decreases the electrical conductivity.

\section{Figure 6}

Conductivity of Bronze composites using both MWNTs and SWNTs were investigated. The conduction occurs essentially through the outermost nanotubes. In case of MWNTs, the interactions with the internal coaxial nanotubes may lead to variations in the electronic properties. However, metallic SWNTs can sustain huge current densities (max. $10^{9} \mathrm{~A} / \mathrm{cm}^{2}$ ) without being damaged, i.e. about three orders of magnitude higher than copper [29]. Figure 7 shows that the electrical conductivity of CNT-Bronze composites is increased up to $10 \%$ by adding $0.1 \mathrm{wt} \%$ MWNTs and up to $20 \%$ by adding same amount of SWNTs. Higher CNT contents do not increase electrical conductivity more, rather decrease.

\section{Figure 7}

As bronze composites were fabricated from the mixture of elemental powders following basis of liquid phase sintering, CNTs are expected to be interconnected 
within the copper grains by the transient liquid phase of tin melts. Nanotubes are positioned at the grain boundaries of $\mathrm{Cu}$ particles and decrease the electrical resistance by filling and connecting the empty regions of the $\mathrm{Cu}$ matrix. This is how the conductivity of nanotube-based bronze composites is expected to improve.

\section{Conclusion}

Carbon nanotube based copper and bronze composites were successfully fabricated by well-established hot-press sintering method of powder metallurgy. The hardness and electrical properties of the composites were evaluated and found up to $47 \%$ improved hardness of Cu by adding $0.1 \mathrm{wt} \%$ of MWNT in the composites, up to $20 \%$ improved electrical conductivity of Bronze by adding $0.1 \mathrm{wt} \%$ of SWNT in the composites. Thus, nanotubes can improve the hardness of highly conductive-low strength copper metals, whereas electrical conductivity of low conductive-highly strength copper alloys can be improved by using nanotubes as reinforcements in composite materials.

\section{Acknowledgments}

The authors are thankful to Fraunhofer Society and Bögra Technologie GmbH for the project support.

\section{References}

[1] Yu M F, Files B S, Arepalli S and Ruoff R S, Tensile loading of ropes of single wall carbon nanotubes and their mechanical properties Phys. Rev. Lett. 84 5552-5 (2000). 
[2] Yu M F, Lourie O, Dyer M J, Moloni K, Kelly T F and Ruoff R S, Strength and breaking mechanism of multiwalled carbon nanotubes under tensile load Science $\mathbf{2 8 7}$ $637-40$ (2000).

[3] Wong E W, Sheehan P E and Lieber C M, Nanobeam mechanics: elasticity, strength, and toughness of nanorods and nanotubes Science 277 1971-5 (1997).

[4] Treacy M M J, Ebbesen T W and Gibson J M, Exceptionally high Young's modulus observed for individual carbon nanotubes Nature 381 678-80 (1996).

[5] Yakobson B I, Brabec C J and Bernholc J, Nanomechanics of carbon tubes: instabilities beyond linear response Phys. Rev. Lett. 76 2511-4 (1996).

[6] Lu J P, Elastic properties of carbon nanotubes and nanoropes Phys. Rev. Lett. 79 1297-300 (1997).

[7] Walters D A, Ericson L M, Casavant M J, Liu J, Colbert D T, mith K A and Smalley R E, Elastic strain of freely suspended single-wall carbon nanotube ropes Appl. Phys. ett. 74 3803-5 (1999).

[8] Wagner H D, Lourie O, Feldman Y and Tenne R, Stress-induced fragmentation of multiwall carbon nanotubes in a polymer matrix Appl. Phys. Lett. 72 188-90 (1998).

[9] Belytschko T, Xiao S P, Schartz G C and Ruoff R S, Atomistic simulation of nanotube fracture Phys. Rev. B 65235430 (2002).

[10] Iijima S, Brabec C, Maiti A and Bernholc J, Structural flexibility of carbon nanotubes J. Chem. Phys. 104 2089-92 (1996).

[11] Kuzumaki, T., Miyazawa, K., Ichinose, H., and Ito, K, Processing of carbon nanotube reinforced aluminium composite J. Mat. Res. 13 2445-2449 (1998). 
[12] Zhan G D, Kuntz J D, Wan J and Mukherjee A K, Single-wall carbon nanotubes as attractive toughening agents in alumina-based nanocomposites Nature Mater. 2 3842 (2002).

[13] Xu C L, Wei B W, Ma R Z, Liang J, Ma X K and Wu D H, Fabrication of aluminum-carbon composites and their electrical properties Carbon 37 855-8 (1999).

[14] Chen X, Xia J, Peng J, Li W and Xie S, Carbon-nanotube metal-matrix composite prepared by electroless plating Compos. Sci. Technol. 155 274-8 (2002).

[15] Kuzumaki T, Ujiie O, Ichinose H and Ito K, Mechanical characteristics and preparation of carbon nanotube fiber reinforced Ti composite Adv. Eng. Mater. 2 416-8 (2000).

[16] Lau K-T and Hui D, The revolutionary creation of new advanced materials-carbon nanotube composite Composites B 33 263-77 (2000).

[17] Lau K-T and Hui D, Effectiveness of using carbon nanotubes as nanoreinforcements for advanced composite structures Carbon 40 1605-6 (2002). [18] Frankland S J V, Harik V M, Odgeard G M, Brenner D W and Gates T S, The stress-strain behavior of polymer- nanotube composites from molecular dynamics simulation Compos. Sci. Technol. 63 1655-61 (2003).

[19] Feng Y, Yuan H L and Zhang M, Fabrication and properties of silver-matrix composites reinforced by carbon nanotubes Mater. Charact. 55 211-8 (2005). [20] Xu C L, Wei B Q, Ma R Z, Liang J, Ma X K andWu D H, Fabrication of aluminum-carbon nanotube composites and their electrical properties Carbon 37 855-8 (1999). 
[21] Uddin S. M, Mahmud T, Wolf C, Glanz C, Kolaric I, Hulman M, Neubauer E, Roth S, Thermal Expansion Coefficient of Nanotube-Metal Composites Physica Status Solidi B 246, No. 11-12, 2836-2839 (2009).

[22] Maksimović V, Pavlović Lj, Pavlović M, Tomić M, Characterization of copper powder particles obtained by electrodeposition MJoM Vol 15 (1) p. 19-27(2009).

[23] http://www.ahwahneetech.com/

[24] M. G. Pavlovi, LJ. J. Pavlovi, E. R. Ivanovi, V. Radmilovi and K. I. Popov The effect of particle structure on apparent density of electrolytic copper powder, J. Serb. Chem. Soc. 66 (11-12) 923-933 (2001).

[25] K. T. Kim, S. I. Cha, S. H. Hong, S. H. Hong, Microstructure and tensile behavior of carbon nanotube reinforced $\mathrm{Cu}$ matrix nanocomposites, Mat. Sci. and Eng. A 430, 27-33 (2006).

[26] Uddin S. M, Mahmud T, Wolf C, Glanz C, Volkmer C, Höller H, Wienecke U, “Verbundkörper aus Kupfer oder einer Kupferlegierung mit eingelagertem Carbon Nanotubes und Verfahren zur Herstellung eines solchen Körpers sowie Verwendung des Verbundkörpers”, Deutsche Patent (DE 102008056750 A1), 12 May, 2010.

[27] D.L. Erich, Metal Matrix Composites: Problems, Applications and Potential in the P/M Industry Int. J. Powder Metall, Vol 23 (No. 1), p 45 (1987).

[28] O. Hjortstam, P. Isberg, S. Söderholm and H. Dai, Can we achieve ultra-low resistivity in carbon nanotube-based metal composites? Appl. Phys. A 78, 1175-1179 (2004).

[29] C. T. White and T. N. Todorov Armchair carbon nanotubes as long ballistic conductors Nature 393, 240 (1998). 
Table 1: Specification of carbon nanotubes

\begin{tabular}{|c|c|c|c|c|}
\hline Type & $\begin{array}{c}\text { Average } \\
\text { diamete }(\mathbf{n m})\end{array}$ & $\begin{array}{c}\text { Range of length } \\
(\boldsymbol{\mu m})\end{array}$ & $\begin{array}{c}\text { Method of } \\
\text { Synthesis }\end{array}$ & $\begin{array}{c}\text { Producer/ } \\
\text { Supplier }\end{array}$ \\
\hline MWNT & $10-20$ & $0.5-200$ & CVD & Ahwahnee \\
\hline SWNT & $<2 \mathrm{~nm}$ & $5-20$ & CVD & Shenzhen \\
\hline
\end{tabular}

Table 2: Specification of metal particles

\begin{tabular}{|c|c|c|c|c|}
\hline Metal powders & $\begin{array}{c}\text { Particle size } \\
(\boldsymbol{\mu m})\end{array}$ & $\begin{array}{c}\text { Particle } \\
\text { shape }\end{array}$ & Method of synthesis & $\begin{array}{c}\text { Producer/ } \\
\text { Supplier }\end{array}$ \\
\hline $\mathrm{Cu}$ & 3 & dendritic & Electrolytic deposition & Sigma-Aldrich \\
\hline $\mathrm{Cu}$ & 10 & spherical & Gas/water atomization & Sigma-Aldrich \\
\hline $\mathrm{Cu}$ & 45 & spherical & Gas/water atomization & TLS \\
\hline $\mathrm{Sn}, \mathrm{Zn}, \mathrm{Ni}$ & 45 & spherical & Gas/water atomization & TLS \\
\hline
\end{tabular}


Table 3: Optimizing Sintering parameters with respect to relative density of the composites

\begin{tabular}{|c|c|c|c|c|c|c|c|}
\hline Composition & $\begin{array}{c}\text { Metal } \\
\text { particle } \\
\text { size }(\boldsymbol{\mu m})\end{array}$ & $\begin{array}{c}\text { Metal } \\
\text { particle } \\
\text { shape }\end{array}$ & $\begin{array}{c}\text { Sintering } \\
\text { Temperatur } \\
\left({ }^{\circ} \mathbf{C}\right)\end{array}$ & $\begin{array}{c}\text { Sintering } \\
\text { Pressure } \\
(\mathbf{M P a})\end{array}$ & $\begin{array}{c}\text { Theoritical } \\
\text { Density } \\
\left(\mathbf{g} / \mathbf{c m}^{\mathbf{3}}\right)\end{array}$ & $\begin{array}{c}\text { Measured } \\
\text { Density } \\
\left(\mathbf{g} / \mathbf{c m}^{\mathbf{3}}\right)\end{array}$ & $\begin{array}{c}\text { Relative } \\
\text { Density } \\
(\boldsymbol{\%})\end{array}$ \\
\hline $\mathrm{Cu}$ & 45 & Spherical & 700 & 30 & 8.90 & 8.54 & 95.96 \\
\hline $\mathrm{Cu}$ & 45 & Spherical & 726 & 30 & 8.90 & 8.58 & 96.40 \\
\hline $\mathrm{Cu}$ & 45 & Spherical & 750 & 30 & 8.90 & 8.68 & 97.53 \\
\hline $\mathrm{Cu}$ & 45 & Spherical & 750 & 40 & 8.90 & 8.77 & 98.54 \\
\hline $\mathrm{Cu}$ & 10 & Spherical & 750 & 40 & 8.90 & 8.84 & 99.33 \\
\hline $\mathrm{Cu}$ & 3 & Dendritic & 750 & 40 & 8.90 & 8.68 & 97.53 \\
\hline $\mathrm{Cu}-0.1 \mathrm{wt} \% \mathrm{CNT}$ & 3 & Dendritic & 750 & 40 & 8.81 & 8.53 & 96.82 \\
\hline $\mathrm{Cu}-0.5 \mathrm{wt} \% \mathrm{CNT}$ & 3 & Dendritic & 750 & 40 & 8.73 & 8.33 & 95.42 \\
\hline $\mathrm{Cu}-0.5 \mathrm{wt} \% \mathrm{CNT}$ & 10 & Spherical & 750 & 40 & 8.73 & 8.46 & 96.91 \\
\hline $\mathrm{Cu}-0.5 \mathrm{wt} \% \mathrm{CNT}$ & 45 & Spherical & 750 & 40 & 8.73 & 8.45 & 96.79 \\
\hline $\mathrm{Cu}-1 \mathrm{wt} \% \mathrm{CNT}$ & 45 & Spherical & 750 & 40 & 8.56 & 8.02 & 93.69 \\
\hline $\mathrm{Cu}-2 \mathrm{wt} \% \mathrm{CNT}$ & 45 & Spherical & 750 & 40 & 8.25 & 7.51 & 91.03 \\
\hline $\mathrm{Cu}-4 \mathrm{wt} \% \mathrm{CNT}$ & 45 & Spherical & 750 & 40 & 7.69 & 6.35 & 82.57 \\
\hline Bronze & 45 & Spherical & 750 & 40 & 8.90 & 8.34 & 93.71 \\
\hline Bronze & 45 & Spherical & 800 & 40 & 8.90 & 8.62 & 96.85 \\
\hline $\begin{array}{c}\text { Bronze- } \\
0.1 w t \% C N T\end{array}$ & 45 & Spherical & 800 & 40 & 8.81 & 8.45 & 95.91 \\
\hline Bronze- & 45 & Spherical & 800 & 40 & 8.73 & 8.19 & 93.81 \\
\hline Bronze-1wt\%CNT & 45 & Spherical & 800 & 40 & 8.56 & 7.61 & 88.90 \\
\hline Bronze-2wt\%CNT & 45 & Spherical & 800 & 40 & 8.25 & 7.42 & 89.94 \\
\hline Bronze-4wt\%CNT & 45 & Spherical & 800 & 40 & 7.69 & 6.58 & 85.57 \\
\hline
\end{tabular}




\section{Figure 1}

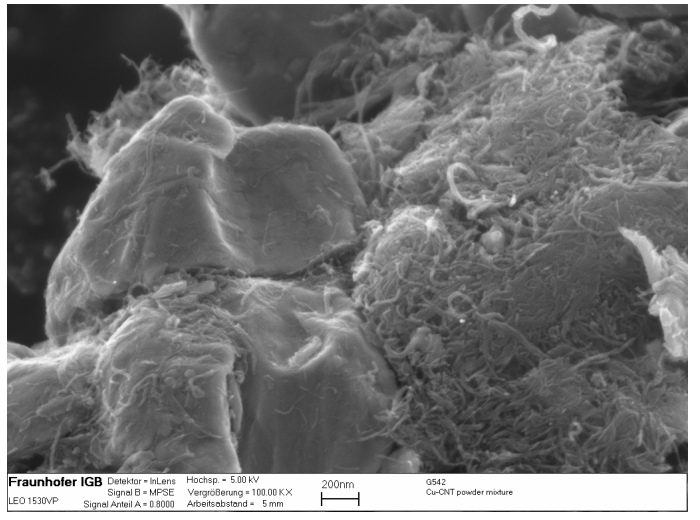

(a) $\mathrm{Cu}(3 \mu \mathrm{m}$, dendritic) - MWNT $(0.5$

wt\%) milled for 1 hour

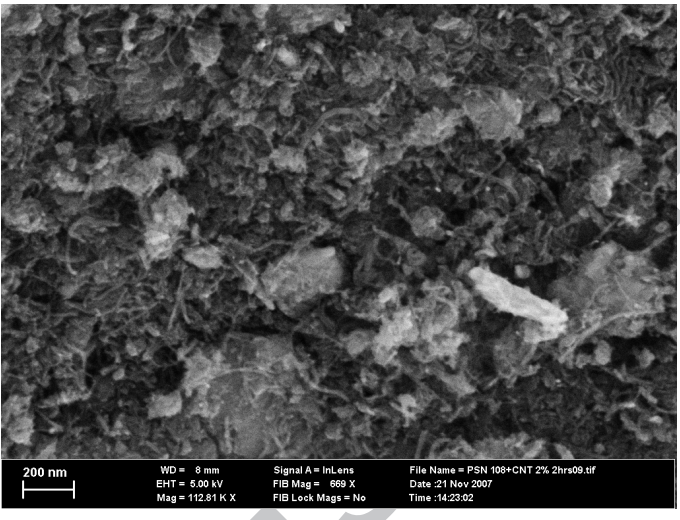

(b) Bronze-MWNT (2 wt $\%$ ) milled for 2 hours

Fig. 1 Evaluation of MWNT - Cu/Bronze milled powders by Scanning Electron Micrographs (SEM)

Figure 2
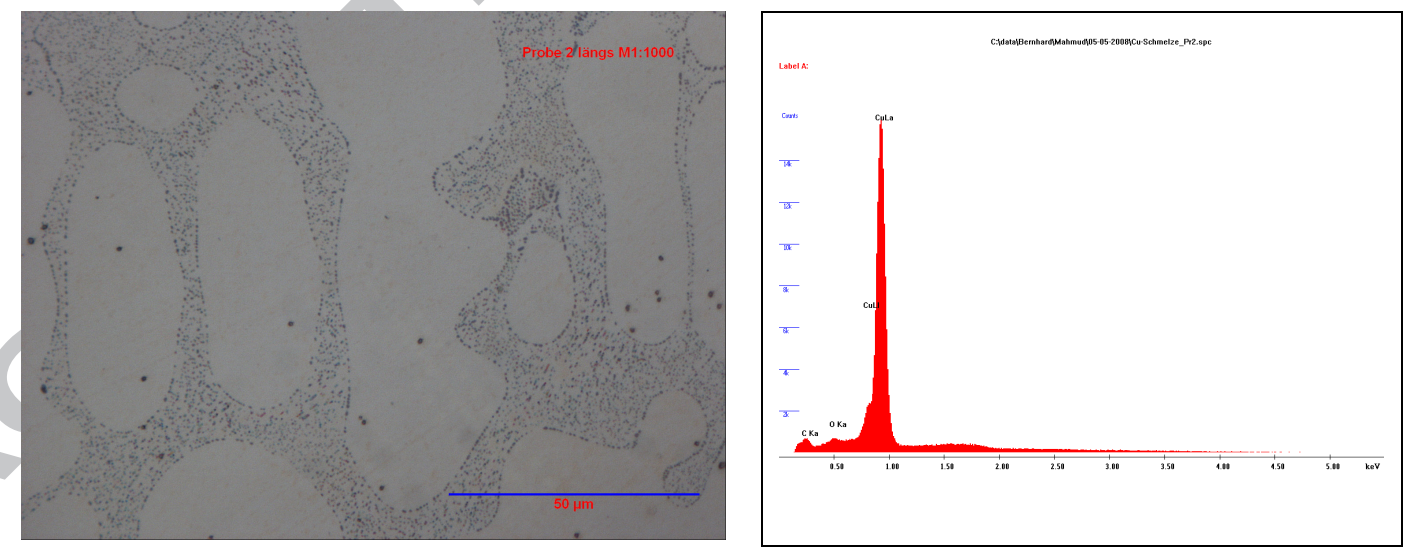

Fig. 2 Optical micrograph (a) and EDX analysis (b) of Cu-MWNT (0.5 wt\%) composite 


\section{Figure 3}

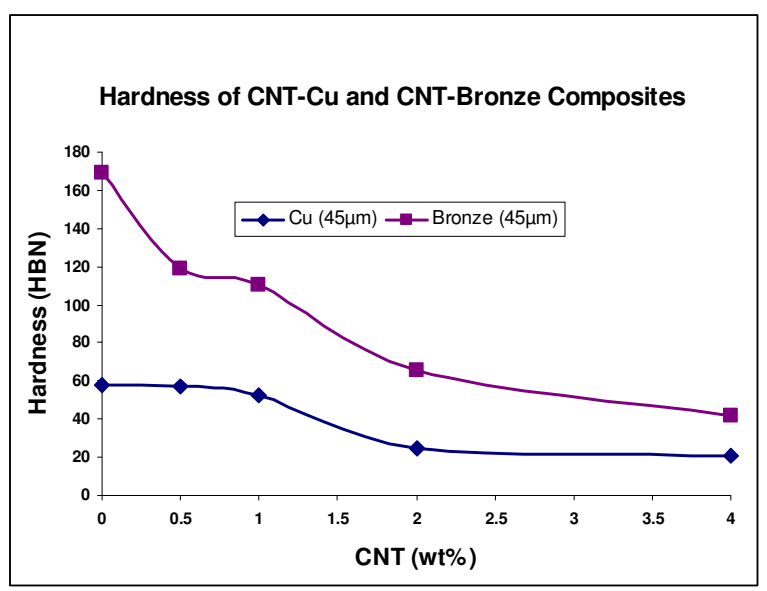

Fig. 3 Hardness of MWNT-Cu and MWNT-Bronze composites

Figure 4

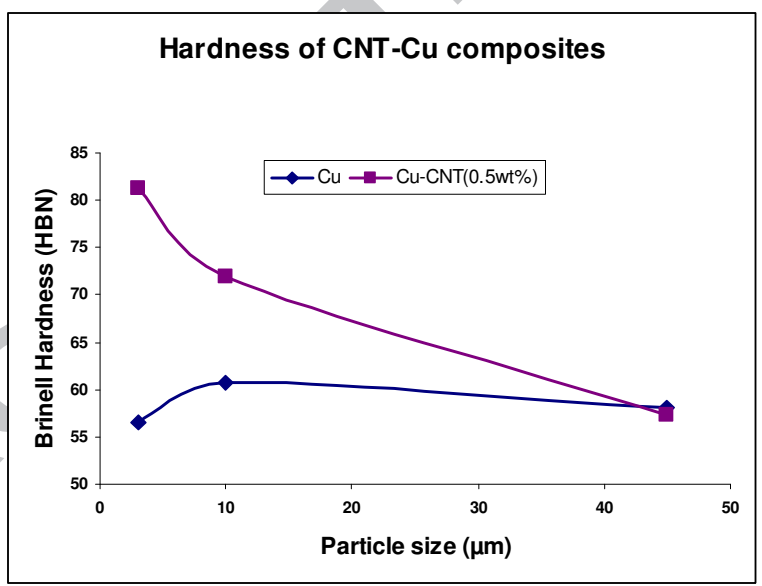

Fig. 4 Hardness of MWNT-Cu composites fabricated with different metal particles 


\section{Figure 5}

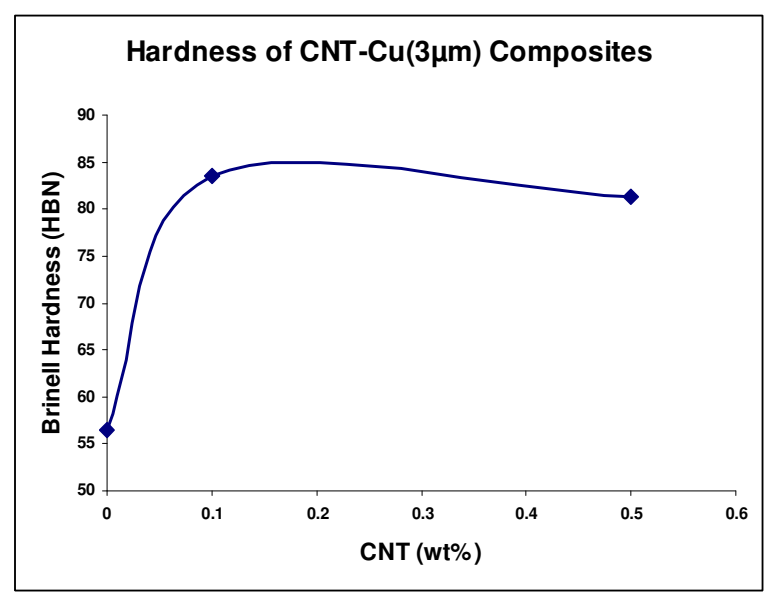

Fig. 5 Hardness of MWNT-Cu $(3 \mu \mathrm{m})$ composites

\section{Figure 6}

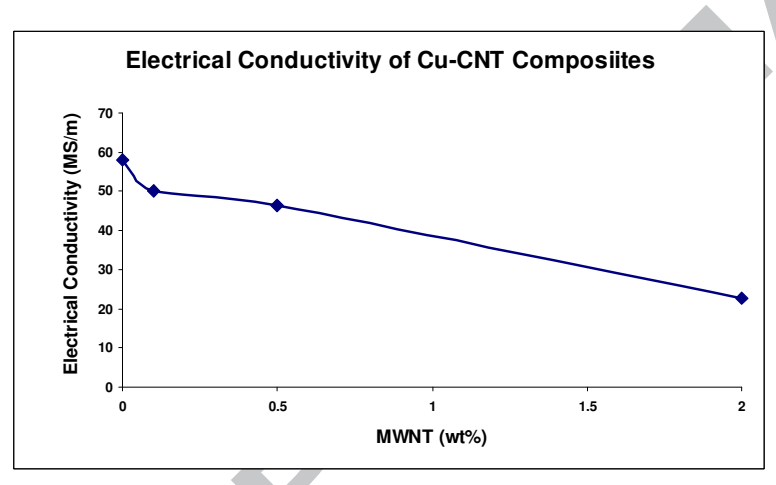

Fig. 6 Electrical conductivity of CNT-Cu composites by using MWNTs 


\section{Figure 7}

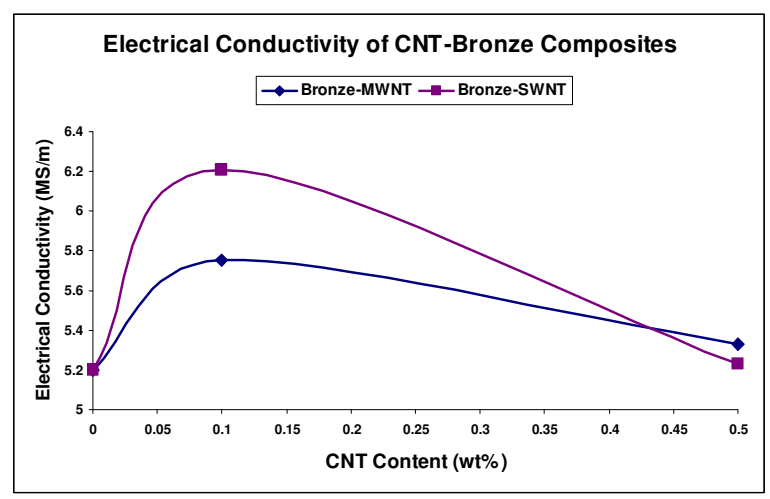

Fig. 7 Electrical conductivity of CNT-Bronze composites by using MWNTs and

\section{SWNTs}

